\title{
Strategic and Interactive Writing Instruction: An Efficacy Study in Grades 3-5
}

\author{
Kimberly Wolbers ${ }^{1}$, Hannah Dostal ${ }^{2}$, Steve Graham ${ }^{3}$, Lee Branum-Martin ${ }^{4}$, \\ Jennifer Kilpatrick ${ }^{5} \&$ Rachel Saulsburry ${ }^{1}$ \\ ${ }^{1}$ College of Education, Health, and Human Sciences, University of Tennessee, Knoxville, Tennessee, USA \\ ${ }^{2}$ Neag School of Education, University of Connecticut, Storrs, Connecticut, USA \\ ${ }^{3}$ Mary Lou Fulton Teachers College, Arizona State University, Tempe, Arizona, USA \\ ${ }^{4}$ College of Education \& Human Development, Georgia State University, Atlanta, Georgia, USA \\ ${ }^{5}$ College of Education and Human Services, University of North Florida, Jacksonville, Florida, USA \\ Correspondence: Kimberly Wolbers, A214 Bailey Education Complex, 1122 Volunteer Blvd, Knoxville, \\ Tennessee, 37996, USA. Tel: 1-865-974-2375. E-mail: kwolbers@utk.edu
}

Received: January 23, 2018 Accepted: February 19, 2018 Online Published: March 5, 2018

doi:10.5539/jedp.v8n1p99 URL: http://doi.org/10.5539/jedp.v8n1p99

\begin{abstract}
A quasi-experimental study was conducted to examine the impact of Strategic and Interactive Writing Instruction on 3rd-5th grade deaf and hard of hearing students' writing and written language compared to a business-as-usual condition (treatment group $N=41$, comparison group $N=22$ ). A total of 18 hours of instruction was provided for each of two types of writing - personal narrative and persuasive. Writing samples, collected prior to instruction and after, were scored for writing traits, written language accuracy, and complexity. Data were analyzed using a two-level, mixed-effects regression. Results show the treatment to be effective for personal narrative and persuasive writing traits, and personal narrative written language variables, with effect sizes ranging from 0.46 to 2.01. Treatment effects were also substantial for persuasive writing written language outcomes (0.38 to 1.06$)$, although not all were statistically significant at the 0.05 level. The findings suggest the importance of apprenticeship in writing and consideration for the specific language needs of students with hearing loss.
\end{abstract}

Keywords: deaf, elementary, writing instruction

\section{Introduction}

\subsection{Introduce the Problem}

Despite advancements in technologies, earlier identification of hearing loss, and greater access to the general education curriculum over the past several decades, low literacy outcomes persist among deaf and hard of hearing (d/hh) students (O’Neill, Arendt, \& Marschark, 2014; Qi \& Mitchell, 2012). One consideration is that d/hh children have unique language histories that impact literacy. Further, reviews of research of writing instruction with $\mathrm{d} / \mathrm{hh}$ students raise alarm that there is little evidence to inform practice (Strassman \& Schirmer, 2012; Williams \& Mayer, 2015), thus, there is a need for interventions that draw upon evidence-based writing practices while accommodating for language differences among $\mathrm{d} / \mathrm{hh}$ students.

Prior research from approximately 2007 to 2012 shows Strategic and Interactive Writing Instruction (SIWI) - an approach to writing instruction founded on evidence-based approaches used with typical and struggling hearing writers, combined with linguistic and metalinguistic components addressing the diverse language needs of $\mathrm{d} / \mathrm{hh}$ students - to have a beneficial impact on the writing and language outcomes of $\mathrm{d} / \mathrm{hh}$ students in grades 6-8 (Dostal, Bowers, Wolbers, \& Gabriel, 2015; Dostal \& Wolbers, 2014; Wolbers, 2008a, 2008b, 2010; Wolbers, Bowers, Dostal, \& Graham, 2013; Wolbers, Dostal, \& Bowers, 2012). The focus of the current study is to examine the extent to which SIWI impacts the discourse-level writing and written language achievement of $\mathrm{d} / \mathrm{hh}$ students when implemented in grades 3-5. While data from a single case design study suggest SIWI is a promising practice at this level (Wolbers et al., 2015), the current study is the first quasi-experimental study examining implementation of SIWI with elementary aged children who often experience more pronounced language delays. 


\subsection{Explore Importance of the Problem}

Learning to become a skilled writer is a challenging task. In addition to learning how to carry out the basic production processes involved in creating text (planning, drafting, revising, and editing), learning to write also includes acquiring knowledge about writing (e.g., text purposes and features), language, audiences, and writing topics. In order to engage in various composing processes, learning to write also requires developing schemas and problem solving strategies, as well as regulating beliefs about writing to sustain effort and engagement (Flower \& Hayes, 1980; Graham, in press; Hayes \& Flower, 1980; Hayes, 1996, 2006). The writing development of d/hh students may be especially compromised due to the lack of fully accessible instruction and practice in these areas, and the lack of approaches aligned with their specific language needs.

D/hh students demonstrate a broad range of language and literacy competencies (e.g., Allen \& Anderson, 2010; Morere \& Allen, 2012; Parasnis, 1998) resulting from diverse early language experiences. Some d/hh students learn spoken English as their first language and are thus learning to read and write in their primary language. These students may have limited access to spoken language depending on their particular hearing loss and amplification options. Secondly, a small percentage of students acquire American Sign Language (ASL) naturally in the home (Mitchell \& Karchmer, 2004) and are developing literacy skills in English as a second language. Finally, many students do not have sufficient access to neither English nor ASL during early development, which can lead to delays in both languages that severely compromise literacy development and academic performance (cf. Lederberg \& Spencer, 2001; Singleton, Morgan, DiGello, Wiles, \& Rivers, 2004). We argue that for literacy interventions to be effective with $\mathrm{d} / \mathrm{hh}$ children, they must flexibly address their unique and diverse language needs; this may include English enrichment instruction, bilingual literacy practices, and/or further language acquisition of ASL and English. While there are research studies with $\mathrm{d} / \mathrm{hh}$ students investigating the impact of evidence-based writing instruction (such as engaging students in process writing, teaching writing strategies, or using writing models), the outcomes are "equivocal" (Strassman \& Schirmer, 2012, p. 166). Only a few of these previous studies have considered the specific language needs of $\mathrm{d} / \mathrm{hh}$ students. SIWI is one approach to writing instruction with $\mathrm{d} / \mathrm{hh}$ students that embeds evidenced practices implemented with hearing writers but also includes specialized approaches for addressing the language needs of $\mathrm{d} / \mathrm{hh}$ children.

\subsection{Describe Relevant Scholarship}

SIWI is a framework for writing instruction guided by three major principles: (1) strategic instruction, (2) interactive instruction, and (3) linguistic competence and metalingustic knowledge. The first two principles incorporate evidence-based practices drawn from research with typically developing and struggling writers (see reviews by Graham, McKeown, Kiuhara, \& Harris, 2012; Graham \& Perin, 2007). The third major principle is designed to address the specific language needs of $\mathrm{d} / \mathrm{hh}$ children. SIWI also involves writing with an authentic purpose and audience, and balancing instruction to attend to both discourse level writing objectives and language objectives at the word and sentence levels. The theoretical assumptions driving the instructional principles in SIWI and examples of instructional enactment are detailed below.

\subsubsection{Strategic Writing Instruction}

Strategic instruction is informed by cognitive theories of composing (Applebee, 2000; Flower \& Hayes, 1980; Hayes \& Flower, 1980; Hayes, 1996, 2006). This principle is aimed at developing strategic writers by teaching the skills and processes of expert writers. Writing processes, strategies, and skills are explicitly taught to students and then practiced during meaningful writing activities with the support of procedural facilitators (Scardamalia \& Bereiter, 1986), such as cue cards, mnemonics or visual scaffolds. For example, the mnemonic GOALS (i.e., Got ideas?, Organize, Attend to language, Look again, and Share), was developed to teach d/hh elementary students the writing process. The GOALS mnemonic is visually presented to students in a circle around the word "Write". An arrow encircles the word "Write" to indicate that students may write and return to any sub-process at any time. Both the classroom poster and GOALS student cue cards have this feature to remind students that they may move between stages of the writing processes in a recursive fashion (Hayes \& Flower, 1980; Hillocks, 1995). After teacher modeling and joint practice with visual scaffolds, students gain independence with targeted writing skills or processes, and begin to direct their own performance (Harris, Mason, Graham, \& Saddler, 2002); at this point, the visual scaffolds are no longer needed to support students' writing. Development of the elementary SIWI curriculum largely involved the creation of strategy instruction posters, cue cards, and scaffolds that were visually accessible to students with minimal language skills.

\subsubsection{Interactive Writing Instruction}

The second overarching principle of SIWI is informed by sociocultural theories of teaching and learning (Lave \& 
Wenger, 2003; Vygotsky, 1978, 1994; Wertsch, 1991) which highlight that learning comes about as a result of interactions occurring during mediated, social activities (Thompson, 2013). In the teaching and learning of writing, highly effective strategy instruction programs give attention to the social and cultural practices involved in writing, for interactive approaches play an integral role during instruction (see example in Harris, Graham, Friedlander \& Laud, 2013). Rather than passively receiving information, students learn about writing by actively engaging in guided or shared writing experiences alongside more knowledgeable writers such as the teacher and their peers. Students and teachers share their ideas, build on each other's contributions, and cooperatively determine necessary writing actions. Interactive writing has shown to be an effective way of apprenticing students in the cognitive processes and actions of writers (Englert \& Dunsmore, 2002; Mariage, 2001).

During interactive instruction, principles of dialogic pedagogy (Burbules, 1993; Ward, 1994; Wells, 2000) are enacted, which actively engage students in problem solving. Learning is theorized to occur through interactions, whereby teachers are able to assess students' understandings and provide contingently responsive instruction on a moment to moment basis. This, in turn, leads to the joint construction of meaning. During SIWI, students and teachers negotiate meaning at every stage of the writing process. As students gradually take on greater independence during writing, teachers reciprocally release responsibility of those strengthened writing practices. Implementing practices of dialogic pedagogy are consistently implemented by exemplary teachers of the $\mathrm{d} / \mathrm{hh}$ (Mayer, Akamatsu, \& Stewart, 2002), which we argue is essential for $\mathrm{d} / \mathrm{hh}$ students having significant language delays.

SIWI is similar to the Self-Regulated Strategy Development model (Harris \& Graham, 2009) of writing that has been found to improve the writing performance of both struggling and typical writers (Graham, Harris, \& McKeown, 2013; Graham, Harris, \& Santangelo, 2015). Both of these approaches emphasize teaching students genre-specific strategies for carrying out basic composing processes, place considerable emphasis on interactive dialogue between students and teacher, and apply gradual release models when teaching students how to compose. Due to the unique language histories of $\mathrm{d} / \mathrm{hh}$ children, we argue that strategy instruction and interactive writing are not enough, and an additional guiding principle is needed to account for the specific language needs of the $\mathrm{d} / \mathrm{hh}$ population.

\subsubsection{Linguistic Competence and Metalinguistic Awareness}

The third overarching SIWI principle draws upon language acquisition theory (Jackendoff, 1994; Pinker, 1995) and second language research, whereby there are two routes to developing language knowledge--implicitly and explicitly (Ellis et al., 2009; Krashen, 1994). This principle directs attention to instructional opportunities that develop greater linguistic competence (implicit) as well as instructional approaches for teaching language (explicit).

Students' linguistic competence may grow implicitly, for example, when students are actively involved in problem-solving during interactive writing. Meaningful exchanges with more proficient users of language (ASL or spoken English) create a natural environment capable of furthering acquisition. Oftentimes, communication breakdowns occur with children who haven't had sufficient exposure to accessible language to acquire a strong language foundation. In these cases, the teacher employs repair strategies (c.f., Tye-Murray, 1994) that promote shared understanding amongst participants. Techniques such as drawing, role play, and use of gesture during SIWI occur in a space separate from the English co-constructed text known as the language zone (author, in press). Once understanding is achieved, teachers pair expressive language with the concrete objects, drawings, or movements that are meaningful to students. These aspects are meant to promote greater language acquisition of an accessible language, like ASL.

Frequent readings of the co-constructed English text during guided writing implicitly builds English linguistic competence among $\mathrm{d} / \mathrm{hh}$ students who often do not hear enough of the language to effortlessly acquire it. Rereading one's text is essential to the revising process of writing, and it may also be a way $\mathrm{d} / \mathrm{hh}$ students come to know how English looks, feels, and sounds, similar to a native user. Opportunities for acquisition of English are critically important since implicit competence provides for more efficient writing (Paradis, 2009), and there are many aspects of the language that cannot be explicitly taught. During SIWI, the written text is initially generated from students' expressions and then guided by the teacher to a level just beyond what students can do independently. Therefore, the text serves as comprehensible and slightly advanced input (Krashen, 1994, 2008). In this way, $\mathrm{d} / \mathrm{hh}$ students are provided an avenue to implicit English competence through rereading their ideas in slightly elevated English.

In addition to supporting the growth of implicit language competence, teachers provide explicit language instruction (Krashen, 1994) aimed at developing students' metalinguistic knowledge which can also assist them in 
writing (c.f., Dostal \& Wolbers, 2014). As the need arises, the SIWI teacher goes to the language zone to contrast grammars, explicitly teach linguistic aspects of ASL and/or English, or expand English vocabulary or phrase options (Wolbers, 2010). For example, if a student shares an idea for the co-constructed text by offering a close approximation to English (with minor necessary revisions), the teacher may add the idea to the English co-constructed text. The teacher then prompts the class to reread and edit. However, if the shared idea is far from the English equivalent and cannot be readily written in English due to visual, spatial, gestural, and syntactical properties of the expression, the class will capture the idea in the language zone using videos, pictures, or drawings. The teacher guides the class to identify or distinguish features of the languages, and then construct the equivalent expression in English. After translating the original idea from ASL to English using the language zone, the idea, now in English form, will be added to the class, co-constructed text. During this process, participants build their metalinguistic knowledge of the language(s) through explicit comparison, clarification, and elaboration of language structures (Wolbers, Bowers, Dostal, \& Graham, 2013). With approaches embedded in SIWI that are designed to grow students' linguistic competence and raise metalinguistic awareness, $\mathrm{d} / \mathrm{hh}$ students ultimately have greater linguistic resources to bring to the task of writing.

\subsection{Study Purpose and Hypotheses}

The purpose of this small-scale study is to pilot SIWI in the later elementary grades and begin to examine the extent to which students' writing and language outcomes are impacted across two genres of writing that are routinely taught in elementary--personal narrative and persuasive writing. During SIWI, evidence-based writing instruction practices are embedded along with specialized approaches carried out in the language zone. SIWI is also designed so that students receive instruction on both discourse-level writing objectives and written language objectives during the guided, co-construction of authentic text. Thus, we examine discourse-level writing and sentence-level language variables separately rather than using holistic writing rubrics because we hypothesize an impact on both. We additionally predict that word identification ability will be impacted by SIWI due to the frequent class rereadings of the co-constructed text. Based on previously observed outcomes at the middle grades levels, we have reason to anticipate that students receiving SIWI will make significantly greater gains in each of these areas. The following research question drives the current study: To what extent does SIWI lead to improved outcomes in writing, written language, and word identification among $3 \mathrm{rd}-5$ th grade $\mathrm{d} / \mathrm{hh}$ students?

\section{Method}

The design was quasi-experimental since it did not include randomized assignment. Prior to the study, the treatment group teachers had already been engaged for a year and a half in an Institute of Education Sciences grant project focused on the iterative development of SIWI for use in the later elementary grade levels. At the time of the study, SIWI development for later elementary classes was complete with the exception of having published instructional materials. The purpose of this study was to begin assessing the promise of the intervention while also piloting the procedures that would be used in a randomized-controlled trial (RCT) the subsequent year. The researchers were simultaneously engaged in recruitment for the upcoming RCT and asked the schools and teachers if they would be interested in joining the project one semester early to participate in this quasi-experimental study. Those who joined served as the comparison group.

\subsection{Instructional Setting}

The study took place in 6 programs across 5 eastern and southeastern states of the US. Two programs identified as ASL-English bilingual programs at residential schools for the deaf. It was an expectation of these programs that students would develop competencies in both ASL and English literacy, and possibly oracy depending on the student. Instructional time was given separately to each of the languages. One program housed within in a public school identified as a listening and spoken language (LSL) program, and used no sign language. Three programs identified as total communication (TC) programs at residential schools for the deaf. Teachers communicated with students using an English-influenced sign language while simultaneously speaking English. While random assignment did not occur in this study, an attempt was made to include participants from each type of program into both conditions. The intervention was implemented in classes; there were six classes in the treatment group (i.e., one bilingual, two LSL, and three TC) and four in the comparison group (i.e., one bilingual, one LSL, and two TC).

\subsection{Student Participants}

The study sample consisted of 63 , 3rd-5th grade d/hh students in SIWI treatment $(N=41)$ and business-as-usual (BAU) comparison conditions $(N=22)$. Students were matched by age, grade, and reading level. Reading level was a measure of word identification ability assessed using the SORT-R, a norm-referenced test that has high measured reliability ratings (e.g., test-retest and split-half Spearman-Brown were 0.98 ) and criterion validity (e.g., 
0.83 correlation with Peabody Individual Achievement Test). Independent samples t-test were conducted for age, grade, and reading level to compare these data by group, and none were statistically significant. See Table 1 for descriptive and t-test statistics.

Table 1. Demographic information and test statistics for age, grade, and reading level

\begin{tabular}{|c|c|c|c|c|c|}
\hline & \multicolumn{2}{|c|}{ Treatment } & \multicolumn{2}{|c|}{ BAU } & \multirow{2}{*}{ t-test } \\
\hline & $\mathrm{M}$ & $\mathrm{SD}$ & $\mathrm{M}$ & SD & \\
\hline Age & 10.77 & 1.00 & 10.31 & 2.47 & $\mathrm{t}(58)=1.02, \mathrm{p}=0.31$ \\
\hline Grade & 3.97 & 0.79 & 3.79 & 0.92 & $\mathrm{t}(58)=0.81, \mathrm{p}=0.42$ \\
\hline Reading Level & 60.44 & 24.11 & 71.86 & 44.47 & $\mathrm{t}(61)=-1.12, \mathrm{p}=0.19$ \\
\hline
\end{tabular}

Teachers completed demographic surveys on their students indicating categorical data such as gender, race/ethnicity, level of hearing loss, level of aided hearing loss, primary form of expression, and fluency of expression. While there were no theoretical reasons to suspect that the SIWI program would be differentially effective for children based on any of these variables, the data are useful in fully describing the similarities and differences of student participants by group. Chi-square test statistics are provided in brackets by variable; all tests were non-significant. It was reported that $49 \%$ of treatment group participants were female in contrast to $59 \%$ of students in the comparison group $\left[X^{2}(2, N=63)=3.67, p=0.16\right]$. In terms of racial or ethnic group, $58 \%$ of treatment group students were Caucasian, followed by 30\% African American, 7\% Hispanic/Latino, and 5\% Multiracial. Of comparison group participants, $50 \%$ were African American, followed by $27 \%$ Caucasian, $14 \%$ Hispanic/Latino, and 9\% Multiracial $\left[X^{2}(3, N=60)=5.56, p=0.14\right]$. Unaided levels of hearing loss can be viewed in Table $2\left[X^{2}(5, N=60)=7.60, p=0.18\right]$. Approximately $59 \%$ of treatment group participants used hearing aids, $34 \%$ had at least one cochlear implant, and $7 \%$ did not use amplification of any kind. In the comparison group, $73 \%$ of participants used hearing aids, $18 \%$ had at least one cochlear implant and $9 \%$ did not use amplification. Data on aided hearing losses can also be viewed in Table 2; however, a chi-square test was not conducted since approximately $30 \%$ of these data were not available.

Table 2. Students' unaided and aided levels of hearing

\begin{tabular}{|c|c|c|c|c|}
\hline \multirow{2}{*}{ Levels of Hearing } & \multicolumn{2}{|c|}{ Treatment } & \multicolumn{2}{|c|}{ BAU } \\
\hline & Unaided & Aided & Unaided & Aided \\
\hline $0-15 \mathrm{~dB}$ normal limits & $0 \%$ & $4.9 \%$ & $4.5 \%$ & $9 \%$ \\
\hline $16-25 \mathrm{~dB}$ slight & $0 \%$ & $7.3 \%$ & $0 \%$ & $22.7 \%$ \\
\hline 26-40dB mild & $2.4 \%$ & $39 \%$ & $9.1 \%$ & $36.5 \%$ \\
\hline 41-55dB moderate & $7.3 \%$ & $22.1 \%$ & $13.6 \%$ & $9.1 \%$ \\
\hline 56-70dB moderately-severe & $19.5 \%$ & $7.3 \%$ & $27.4 \%$ & $0 \%$ \\
\hline $71-90 \mathrm{~dB}$ severe & $17.1 \%$ & $2.4 \%$ & $22.7 \%$ & $0 \%$ \\
\hline $91 \mathrm{~dB}+$ profound & $53.7 \%$ & $9.7 \%$ & $22.7 \%$ & $0 \%$ \\
\hline information unavailable & $0 \%$ & $7.3 \%$ & $0 \%$ & $22.7 \%$ \\
\hline
\end{tabular}

Note. BAU $=$ Business as usual.

Table 3. Students' primary form of expression

\begin{tabular}{lll}
\hline Form of Expression & Treatment & BAU \\
\hline ASL or English-influenced ASL & $41.5 \%$ & $59 \%$ \\
Spoken English or Sign Supported Spoken English & $43.9 \%$ & $36.5 \%$ \\
Severe Language Delay & $14.6 \%$ & $4.5 \%$ \\
\hline
\end{tabular}


Teachers indicated the method through which their students primarily expressed themselves. See Table 3. Using a 5-point rating scale from "can express most thoughts fluently" to "can't express most thoughts fluently", teachers rated students' fluency of expression. In the treatment group, $61 \%$ of participants were reported as fluently expressing many to most ideas, and $39 \%$ as having moderate to severe difficulties. This was $64 \%$ and $36 \%$ respectively for comparison group participants $\left[X^{2}(4, N=60)=4.96, p=0.29\right]$.

Nine students in the treatment group were reported as having additional disabilities including Attention Deficit Hyperactivity Disorder (ADHD), Retinitis Pigmentosa or other visual impairment, Auditory Processing Disorder, Cerebral Palsy, fine motor deficits, Intellectual Disability, and Functional Delay. Two students in the comparison group were reported as having ADHD and hypotonia.

\subsection{Teacher Participants}

There were five treatment group teachers who had been involved in the SIWI development work for more than a year, and five comparison group teachers who had no previous exposure to SIWI. All ten teacher participants were white females. Nine of the teachers had a Master's degree, and all held a Bachelor's degree with some additional graduate credits. Years of teaching experience ranged from 3 to 20 years $(M=7.8, S D=6.2)$ for the five treatment group teachers and 7 to 32 years $(M=17.4, S D=10.0)$ for the five comparison group teachers. One of the treatment group participants was a speech therapist and had more limited time with her students--approximately 1 hour each week as opposed to 2 hours per week like the other teachers. There was one deaf teacher in the treatment group and two in the comparison group; all other teacher participants had normal hearing. Teachers who used sign language during instruction were asked to rate their abilities to express ideas in ASL on a 5-point scale, with 5 being an ability to express most anything fluently in ASL. The mean rating of the treatment group teachers was 4 $(S D=0.83)$, and the comparison group teachers' mean rating was $4.6(S D=0.41)$. Teachers also rated their preparation for the teaching of writing (excluding SIWI training) on a 3-point scale (i.e., 3 = exceptional, $2=$ adequate, $1=$ minimal $)$. The BAU teachers' mean rating was $2.4(S D=0.58)$ and the treatment group teachers' mean rating was $1.8(S D=0.52)$. On a 5-point scale, teachers rated how much they like writing; the mean rating of BAU group teachers was $4.6(S D=0.52)$ and the mean rating of treatment group teachers was $4.2(S D=.75)$.

\subsection{Procedures}

The study was implemented across two, nine-week quarters of the academic year. While the total number of implementation weeks varied somewhat across classes, 18 hours of writing instruction per quarter was documented for each class, which equates to approximately 2 hours of instruction per week. Personal narrative writing was taught during the first quarter, followed by one quarter of persuasive writing instruction. Personal narrative writing prompts were administered by teachers in class at the beginning of the study (pre), after the first quarter (post), and at the conclusion of the study (maintenance). Independent writing samples were collected from each student. The average administration time was 20 minutes; however, students were allowed more time to respond in writing if needed. The personal narrative prompt asked students to tell of an experience or happening in their lives that they would like to share with others. Persuasive writing samples were collected at the beginning of the second quarter (pre) and end of the quarter (post). As an example, one persuasive writing prompt asked students to write a letter to a parent or guardian with reasons why they should be allowed to get a new pet. Because there was more than one persuasive writing prompt, the prompt topics were equally distributed and alternated across treatment and comparison groups. Lastly, teachers collected word identification from their students at the start and conclusion of the study using the SORT-R3. This assessment was administered individually and took approximately 5-15 minutes per student.

\subsubsection{SIWI Group Instruction}

Teachers in the treatment group provided instruction on writing personal narratives and persuasive essays by enacting SIWI driving principles of strategic instruction, interactive instruction, and linguistic competence and metalinguistic awareness. A unit of guided, group instruction begins with establishing an audience and purpose for the writing, and ends with publication. During the unit, the students collaboratively engage in all aspects of the writing process, using strategic and visual tools as needed. The teacher guides students' thinking and talking around specific aspects of the writing process aligned with individual and class objectives (e.g., planning and organizing ideas for writing, or rereading and revising the writing). Upon student participation through idea sharing or pen sharing, the teacher dynamically assesses the students' levels of understanding and provides contingently responsive feedback to guide the lesson forward. The teacher moves to the language zone to repair communication breakdowns, guide and support translation skills, and/or enrich English vocabulary or phrase use. The teacher also makes decisions on when and how to transition from guided writing to shared and/or independent writing. The teacher may, for example, start a lesson in guided writing format, request students breakout into 
partners or individually to work on particular skills, and then return to the full group for sharing and feedback. S/he may also split the time spent in guided writing with separate but parallel independent or shared writing opportunities. The teacher makes these decisions based on the amount of control s/he has successfully transferred to students in their objective areas during guided writing, and the amount of support that is needed to challenge but not frustrate students.

\subsubsection{Instructional Fidelity of Intervention Agents}

One instructional unit is used to measure teachers' fidelity, which allows for the observation of instructional principles that are only demonstrated during parts of the writing process. The first and second authors rated teachers' instructional fidelity using a SIWI Observation and Fidelity Instrument (SIWI-OFI). During the first year of the grant project, the researchers regularly rated the same lessons and then compared scoring to achieve high levels of reliability, $>85 \%$. The SIWI-OFI provides an overall implementation percentage based on 53 items that are scored with a 1 (incorporated instructional element faithfully), 0.5 (implements principle irregularly), or 0 (did not incorporate). During the current study, the researchers watched videotaped lessons from at least one personal narrative unit and one persuasive unit implemented by each teacher. Teachers' percentages of fidelity to SIWI ranged from $60.4 \%-89 \%$ with an average of $75 \%$. Due to the low percentage of fidelity, we examined the data more fully to provide greater detail regarding implementation. Fidelity percentages did not differ by genre but did differ by subcategories on the SIWI-OFI. Subcategories on the SIWI-OFI align with major driving principles of strategic instruction, interactive instruction, and linguistic competence and metalinguistic awareness. Overall, teachers incorporated more instructional principles associated with interactive instruction as compared to the other two subcategories. Principles associated with interactive instruction are perhaps more demanding of the teachers' cognitive resources since instructional decision making happens moment to moment as a result of dynamic assessment. Once interactive instruction becomes more automatic and natural for teachers, other areas begin to undergo refinement. Indeed, this interpretation of the fidelity data corroborates with findings from a previous study in which researchers examined the impact of the 3-year SIWI professional development (PD) program on teacher implementation fidelity. Teachers performed at $74 \%$ fidelity on average after 1 year of SIWI PD, $85 \%$ after 2 years, and $94 \%$ after 3 years (Wolbers, Dostal, Skerrit \& Stephenson, 2016). It is clear that teachers need ongoing, longitudinal PD with supported practice to advance their knowledge of and ability to faithfully implement SIWI. While higher instructional fidelity is surely associated with a stronger impact on student outcomes, there is also evidence that teachers have a positive impact on student outcomes even after one year of SIWI PD (e.g., Wolbers et al., 2015). While four of the five treatment group teachers had previously attended information sessions on SIWI in the middle grades, it was their first experiences with the SIWI PD program designed for elementary classes and thus we regard them as first year SIWI teachers.

\subsubsection{Comparison Group Instruction}

Comparison group teachers were asked to indicate the amount of time spent weekly on writing, reading, or language arts, and to describe their literacy instruction practices. Teachers reported spending 8-12 hours a week on literacy, with approximately 3-5 hours of that time focused on writing and language arts. Whereas treatment group teachers spent a similar number of hours weekly on literacy instruction, they implemented SIWI approximately 2 hours a week. When asked to describe their writing instruction, all comparison group teachers reported incorporating English grammar practice (e.g., parts of speech, sentence structure and syntax, word scramble worksheets, using spelling or vocabulary in semantically appropriately ways). The next most commonly reported practices included engaging students in process writing (e.g., brainstorming, organizing using graphic organizer, drafting, conferencing with teacher to revise), teaching mechanics of writing (e.g., capitalization, punctuation), and exposing students to different genres of writing (e.g., persuasive, expository, personal narrative). Three teachers reported that their students write about the stories they read. Instructional practices reported by one teacher each include: using model text to illustrate author techniques, teaching text structure or language; publishing one's writing and sharing with the class; translating between ASL and English.

\subsection{Scoring}

We report on 6 measures of writing and 10 measures of written language associated with the personal narrative and persuasive writing samples, and 1 measure of SORT-R3 word identification ability. Administration and scoring of the SORT-R3 was completed by the classroom teachers. Scoring of writing measures was completed by the sixth author, after achieving sufficient interrater reliability with the second author. Scoring of written language measures was completed by the fifth author, after achieving sufficient interrater reliability with the first author. The process for establishing interrater reliability involved two raters scoring rounds of 10 samples at a time. After each round, raters would discuss and then come to consensus on different scores. Consensus scores were included in the 
analysis. Raters continued to double score rounds of data until at least $20 \%$ of each genre was scored and interrater reliability was 0.85 or higher on each measure. Scoring is further detailed below.

\subsubsection{Writing}

Three measures for discourse-level writing skills associated with each genre were scored. The measures were drawn from the $4^{\text {th }}$ grade National Assessment of Educational Progress rubrics (NAEP; National Assessment Governing Board, U.S. Department of Education, 2010), and followed the same six-point rating scale (i.e., 1 = little to no skill, 6 = effective skill). Because of our intention to examine written language variables separately and more intensely, we did not include grammar or conventions in the writing rubrics. We used individual trait rubrics for evaluating the writer's skill in introducing, developing, and organizing one's ideas. Specific traits associated with personal narrative writing included one's ability to orient the reader to an event, describe events using sensory details, and organize one's writing, including clear sequencing of events. For example, a score of 1 would be given for description of events to a writer who does not tell any events or tells information that is off topic; a score of 6 would represent the telling of many events that are on topic and the inclusion of great sensory details. Traits associated with persuasive writing included one's ability to formulate a clear opinion, provide convincing reasons and examples, and organize one's argument effectively. For example, a score of 1 on formulating an opinion would be given to writers who do not tell their opinions, and a score of 6 would be given to writers who tell their opinions clearly and create high reader interest.

When raters began scoring to obtain interrater reliability, there were discrepancies across raters that were related to students' command of English. Since students with more significant language delays have fewer language resources available to demonstrate improved discourse-level writing skills, this caused raters to sometimes underestimate scores for these students while overestimating scores for students with greater English linguistic competence. To address this problem and increase reliability, pre and post samples from the same student were scored in succession. This allowed raters to evaluate individual student growth and reduce the influence of language on scoring. The samples remained blinded so that raters did not know class, student name, or whether the samples were associated with treatment or comparison groups. The intraclass correlation coefficients associated with scoring personal narrative samples for orientation, events, and organization were $0.90,0.97$, and 0.86 respectively. The intraclass correlation coefficients for scoring persuasive samples for opinion, reasons and organization were $0.92,0.97$, and 0.99 . These correlations indicate good internal consistency between raters.

\subsubsection{Written Language}

There were five language measures for each genre of writing drawn from the Structural Analysis of Written Language (SAWL; White, 2007). We chose a measure that would be sensitive to the unique language challenges of $\mathrm{d} / \mathrm{hh}$ students. The SAWL was designed, specifically with $\mathrm{d} / \mathrm{hh}$ students in mind, to track language clarity and complexity indicators in writing, and it allows for quantitative analysis of observed changes. Dr. White, developer of the SAWL, conducted a 2-day training session for the research team at the beginning of the study.

The SAWL was used to score the writing samples for three levels of word efficiency ratio (WER), words per t-unit, and percentage of complete sentences. A T-unit is the shortest grammatical sentence--independent clause plus any dependent clauses (Hunt, 1965). WER I represents the ratio of perfect t-units, WER II represents the ratio of perfect t-units plus any flawed units containing all of the major grammar constituents, and WER III represents the previous two plus perfect word strings of three or more words. Increases in the WER ratios, as well as percentage of complete sentences, suggest greater linguistic accuracy in a student's writing, and increases in words per t-unit indicate greater linguistic complexity (Hunt, 1965). Two researchers scored slightly more than $20 \%$ of the personal narrative and persuasive writing samples; intraclass correlation coefficients indicated good internal consistency between raters for WER I (0.91), WER II (0.95), WER III (0.94), words per t-unit (0.9), and percentage of complete sentences $(0.96)$.

\subsection{Design and Analysis}

Instruction was provided sequentially for personal narrative and persuasive. Students were given pretest measures and then retested after nine weeks of treatment. A maintenance retest was given nine additional weeks after personal narrative instruction ended. Because there were only one to three teachers per school, we modeled clustering at the teacher level, acknowledging that this variability is due to both the instructional group as well as the school. While the sample was small, we modeled the essential design features of pretest, treatment, and clustering due to teacher/instructional group. We fit multilevel models of a posttest predicted by pretest, fit within teacher (i.e., a two level mixed-effects regression or hierarchical linear model). Classrooms contained students in grades three, four, or five. The conceptual form of the analysis model for student $i$ with teacher $j$ has the general 
form:

$$
\text { Posttest }_{i j}=\text { Intercept }_{i j}+\text { Pretest }_{i j}+\text { Treatment }_{j}+\text { Teacher }_{j}+e_{i}
$$

where Posttest $t_{i j}$ and Pretest $t_{i j}$ are the student's respective scores on the outcome, and Intercept $_{i j}$ is the model-predicted mean posttest score when all predictors are zero. Treatment $t_{j}$ is the teacher's randomly assigned status. Teacher $r_{j}$ is a random deviation for the instructional group of the student (i.e., a random intercept term). $e_{i j}$ is random error. Overall, this model estimates treatment effects while controlling for pretest and instructional group differences (at the teacher/classroom level).

A multilevel model similar to Equation 1 (pretest as the outcome, with random variability for teacher) was also fit to all pretest scores to determine whether there were preexisting differences between treatment groups. Several pretests showed that the treatment group started significantly lower than the BAU group. These differences are reported in each of the descriptive statistics tables. While this model includes pretest as a control variable, these pretest differences will be discussed as a limitation. In addition, the model shown in Equation 1 was also fit including effects for grade level differences. No grade effects were significant and the substantive conclusions were the same, so grade effects were excluded for simplicity.

\section{Results}

Table 4 presents results of the multilevel regression for each of the three writing trait outcomes for personal narrative and persuasive writing. As shown in Equation 1, there are three fixed (i.e., average) effects and two random effects (intercept variability due to classroom and residual error). For each outcome, these five parameter results are shown in the Estimate column. For fixed effects, standard error, degrees of freedom, and a $p$-value are shown. For random effects, the variance estimate and a standard deviation are shown. In addition, the rightmost column shows an effect size for the treatment, calculated as the model-predicted mean difference divided by the pooled residual $S D$, akin to a Hedge's $g$ estimate (Hedges, 2007).

Together with the appropriate means from descriptive statistics in Tables 5 and 6, Table 4 gives the model-based estimates of change and treatment in the presence of classroom differences. For example, for the first row regarding personal narrative orientation, the intercept $(0.55)$ and pretest effects $(0.58)$ imply that student with an average pretest score (1.30; Table 4) in an average classroom in the BAU group would have a model-predicted posttest score of $1.30(0.55+0.58 \times 1.30=1.30)$. The treatment effect of 0.46 implies that an average student (with an equal pretest) in the treatment group would score almost half a unit higher on the posttest.

The random effects imply that a classroom one $S D$ higher than average would score 0.45 units higher, and students vary with a $S D$ of 0.86 units. The effect size of 0.53 implies that the treatment resulted in scores one half of a $S D$ higher than the control group. The rest of the effects in Table 4 can be interpreted in a similar manner. Overall, Table 4 shows that the treatment was effective, resulting in effect sizes ranging from 0.53 to 2.01 . 
Table 4. Multilevel model results for personal narrative and persuasive writing

\begin{tabular}{|c|c|c|c|c|c|c|c|c|}
\hline Outcome & Type & Effect & Est. & $S E / S D$ & $d f$ & $t$ & $p$ & Size \\
\hline \multirow[t]{5}{*}{ Personal Narrative Orientation } & \multirow[t]{3}{*}{ Fixed } & Intercept & 0.55 & $(0.34)$ & 15 & 1.62 & 0.13 & - \\
\hline & & Pretest & 0.58 & $(0.15)$ & 33 & 3.77 & $<.01$ & - \\
\hline & & Treatment & 0.46 & $(0.36)$ & 17 & 1.27 & 0.22 & 0.53 \\
\hline & \multirow[t]{2}{*}{ Random } & Intercept & 0.21 & 0.45 & - & - & - & - \\
\hline & & Residual & 0.74 & 0.86 & - & - & - & - \\
\hline \multirow[t]{5}{*}{ Personal Narrative Events } & \multirow[t]{3}{*}{ Fixed } & Intercept & 0.78 & $(0.33)$ & 15 & 2.32 & 0.03 & - \\
\hline & & Pretest & 0.58 & $(0.13)$ & 32 & 4.28 & $<.01$ & - \\
\hline & & Treatment & 0.65 & $(0.29)$ & 16 & 2.27 & 0.04 & 1.20 \\
\hline & \multirow{2}{*}{ Random } & Intercept & 0.16 & 0.40 & - & - & - & - \\
\hline & & Residual & 0.30 & 0.54 & - & - & - & - \\
\hline \multirow[t]{5}{*}{ Personal Narrative Organization } & \multirow[t]{3}{*}{ Fixed } & Intercept & 0.50 & $(0.40)$ & 14 & 1.23 & 0.24 & - \\
\hline & & Pretest & 0.50 & $(0.13)$ & 52 & 3.82 & $<.01$ & - \\
\hline & & Treatment & 1.11 & $(0.34)$ & 38 & 3.26 & $<.01$ & 2.01 \\
\hline & \multirow[t]{2}{*}{ Random } & Intercept & 0.50 & 0.71 & - & - & - & - \\
\hline & & Residual & 0.31 & 0.55 & - & - & - & - \\
\hline \multirow[t]{5}{*}{ Persuasive Opinion } & \multirow[t]{3}{*}{ Fixed } & Intercept & 0.42 & $(0.31)$ & 16 & 1.34 & 0.20 & - \\
\hline & & Pretest & 0.87 & $(0.11)$ & 22 & 7.95 & $<.01$ & - \\
\hline & & Treatment & 0.57 & $(0.26)$ & 15 & 2.17 & 0.05 & 1.05 \\
\hline & \multirow[t]{2}{*}{ Random } & Intercept & 0.08 & 0.28 & - & - & - & - \\
\hline & & Residual & 0.30 & 0.54 & - & - & - & - \\
\hline \multirow[t]{5}{*}{ Persuasive Reasons } & \multirow[t]{3}{*}{ Fixed } & Intercept & 0.18 & $(0.32)$ & 12 & 0.58 & 0.57 & - \\
\hline & & Pretest & 0.92 & $(0.11)$ & 17 & 8.41 & $<.01$ & - \\
\hline & & Treatment & 0.69 & $(0.28)$ & 15 & 2.49 & 0.03 & 1.44 \\
\hline & \multirow[t]{2}{*}{ Random } & Intercept & 0.13 & 0.35 & - & - & - & - \\
\hline & & Residual & 0.23 & 0.48 & - & - & - & - \\
\hline \multirow[t]{5}{*}{ Persuasive Organization } & \multirow[t]{3}{*}{ Fixed } & Intercept & 0.28 & $(0.28)$ & 11 & 0.98 & 0.35 & - \\
\hline & & Pretest & 0.88 & $(0.10)$ & 14 & 8.92 & $<.01$ & - \\
\hline & & Treatment & 0.60 & $(0.25)$ & 12 & 2.45 & 0.03 & 1.27 \\
\hline & \multirow[t]{2}{*}{ Random } & Intercept & 0.08 & 0.28 & - & - & - & - \\
\hline & & Residual & 0.23 & 0.48 & - & - & - & - \\
\hline
\end{tabular}

Note . Est. $=$ Estimate (regression fixed effects or variance for random effects: see Equation 1). Dashes indicate that an estimate is not applicable. $S E=$ standard error in parentheses. $S D=$ standard deviation for random effect. Size $=$ treatment effect size (divided by the residual $S D$, akin to a Hedges' $g$ ). Analysis of maintenance effects via repeated measures ANOVA (with and without heterogeneous variances and clustering) confirm significant pretest differences and no treatment effects beyond pretest. 
Table 5. Descriptive statistics for personal narrative writing outcomes

\begin{tabular}{|c|c|c|c|c|c|c|c|}
\hline \multirow{2}{*}{ Writing Trait } & \multirow{2}{*}{ Group } & \multicolumn{2}{|c|}{ Pretest } & \multicolumn{2}{|c|}{ Posttest } & \multicolumn{2}{|c|}{ Maintenance } \\
\hline & & $M$ & $S D$ & $M$ & $S D$ & $M$ & $S D$ \\
\hline \multirow[t]{2}{*}{ Orientation } & $\mathrm{BAU}$ & 1.3 & 1.3 & 1.4 & 1.2 & 1.4 & 1.1 \\
\hline & Treatment & 0.7 & 0.7 & 1.4 & 1.1 & 0.8 & 0.9 \\
\hline \multirow[t]{2}{*}{ Events } & BAU & 1.8 & 1.1 & 1.9 & 1.0 & 1.8 & 1.1 \\
\hline & Treatment & $1.2^{*}$ & 0.6 & 2.0 & 0.8 & 1.8 & 0.8 \\
\hline \multirow[t]{2}{*}{ Organization } & BAU & 1.9 & 1.3 & 1.7 & 1.4 & 1.9 & 1.3 \\
\hline & Treatment & $1.2 *$ & 0.7 & 1.9 & 0.8 & 1.7 & 0.8 \\
\hline
\end{tabular}

Note. ${ }^{*}=$ Treatment statistically significantly lower than BAU at pretest $(\mathrm{p}<.05)$.

Table 6. Descriptive statistics for persuasive writing outcomes

\begin{tabular}{|c|c|c|c|c|c|}
\hline \multirow{2}{*}{ Writing Trait } & \multirow{2}{*}{ Group } & \multicolumn{2}{|c|}{ Pretest } & \multicolumn{2}{|c|}{ Posttest } \\
\hline & & $M$ & $S D$ & $M$ & $S D$ \\
\hline \multirow[t]{2}{*}{ Opinion } & BAU & 2.3 & 1.3 & 2.4 & 1.3 \\
\hline & Treatment & $1.1^{*}$ & 0.6 & 2.0 & 0.8 \\
\hline \multirow[t]{2}{*}{ Reasons } & BAU & 2.2 & 1.5 & 2.3 & 1.5 \\
\hline & Treatment & $1.1^{*}$ & 0.5 & 1.8 & 0.9 \\
\hline \multirow[t]{2}{*}{ Organization } & BAU & 2.2 & 1.4 & 2.3 & 1.4 \\
\hline & Treatment & $1.1^{*}$ & 0.6 & 1.9 & 0.8 \\
\hline
\end{tabular}

Note. ${ }^{*}=$ Treatment statistically significantly lower than BAU at pretest $(\mathrm{p}<.05)$.

Table 7 shows the results of the multilevel analysis for the written language outcomes and for the word identification test, following the format of Table 4. Descriptive statistics associated with the language measures are presented in Tables 8 and 9, and those associated with word identification are in Table 10. For the five personal narrative written language outcomes, the treatment effects were moderate to large (0.46 to 1.20$)$. For the five persuasive written language outcomes, treatment effects were also substantial ( 0.38 to 1.06$)$, although not all were statistically significant at the 0.05 level. We suspect that non-significance of persuasive writing language variables is an indication of small sample size since the estimate of treatment effects were comparable to those of personal narrative writing, and the effect sizes were moderate to large (Table 7). The final outcome, word identification measured by the SORT-R3, showed no substantial difference between groups (effect size $=0.11$ ). Students' word identification outcomes varied substantially by teacher.

Table 7. Multilevel model results for language outcomes and word identification

\begin{tabular}{|c|c|c|c|c|c|c|c|c|}
\hline Outcome & Type & Effect & Est. & $S E / S D$ & $d f$ & $t$ & $p$ & Size \\
\hline Personal Narrative & Fixed & Intercept & 0.05 & $(0.06)$ & 15 & 0.87 & 0.40 & - \\
\hline \multirow[t]{4}{*}{ WER I } & & Pretest & 0.43 & $(0.12)$ & 59 & 3.73 & $<.01$ & - \\
\hline & & Treatment & 0.08 & $(0.07)$ & 13 & 1.18 & 0.26 & 0.46 \\
\hline & Random & Intercept & 0.00 & 0.24 & - & - & - & - \\
\hline & & Residual & 0.03 & 0.41 & - & - & - & - \\
\hline Personal Narrative & Fixed & Intercept & 0.11 & $(0.07)$ & 27 & 1.43 & 0.16 & - \\
\hline & & Pretest & 0.75 & $(0.09)$ & 58 & 8.71 & $<.01$ & - \\
\hline & & Treatment & 0.20 & $(0.07)$ & 16 & 2.90 & 0.01 & 1.20 \\
\hline & Random & Intercept & 0.01 & 0.26 & - & - & - & - \\
\hline
\end{tabular}




\begin{tabular}{|c|c|c|c|c|c|c|c|c|}
\hline Outcome & Type & Effect & Est. & $S E / S D$ & $d f$ & $t$ & $p$ & Size \\
\hline & & Residual & 0.03 & 0.41 & - & - & - & - \\
\hline Personal Narrative & Fixed & Intercept & 0.18 & $(0.08)$ & 28 & 2.16 & 0.04 & - \\
\hline \multirow[t]{4}{*}{ WER III } & & Pretest & 0.67 & $(0.09)$ & 58 & 7.45 & $<.01$ & - \\
\hline & & Treatment & 0.18 & $(0.07)$ & 14 & 2.41 & 0.03 & 1.09 \\
\hline & Random & Intercept & 0.01 & 0.30 & - & - & - & - \\
\hline & & Residual & 0.03 & 0.40 & - & - & - & - \\
\hline Personal Narrative & Fixed & Intercept & 1.53 & $(0.62)$ & 16 & 2.48 & 0.02 & - \\
\hline Words per & & Pretest & 0.61 & $(0.09)$ & 40 & 6.78 & $<.01$ & - \\
\hline \multirow[t]{3}{*}{ T-unit } & & Treatment & 1.56 & $(0.55)$ & 9 & 2.84 & 0.02 & 1.13 \\
\hline & Random & Intercept & 0.29 & 0.73 & - & - & - & - \\
\hline & & Residual & 1.91 & 1.17 & - & - & - & - \\
\hline Personal Narrative & Fixed & Intercept & 0.21 & $(0.08)$ & 29 & 2.69 & 0.01 & - \\
\hline$\%$ complete & & Pretest & 0.66 & $(0.08)$ & 59 & 8.47 & $<.01$ & - \\
\hline \multirow[t]{3}{*}{ sentences } & & Treatment & 0.18 & $(0.07)$ & 18 & 2.49 & 0.02 & 1.09 \\
\hline & Random & Intercept & 0.01 & 0.30 & - & - & - & - \\
\hline & & Residual & 0.03 & 0.41 & - & - & - & - \\
\hline Persuasive & Fixed & Intercept & 0.04 & $(0.06)$ & 26 & 0.62 & 0.54 & - \\
\hline \multirow[t]{4}{*}{ WER I } & & Pretest & 0.41 & $(0.14)$ & 60 & 2.93 & $<.01$ & - \\
\hline & & Treatment & 0.08 & $(0.07)$ & 13 & 1.11 & 0.29 & 0.38 \\
\hline & Random & Intercept & 0.00 & 0.14 & - & - & - & - \\
\hline & & Residual & 0.05 & 0.46 & - & - & - & - \\
\hline Persuasive & Fixed & Intercept & 0.11 & $(0.10)$ & 27 & 1.06 & 0.30 & - \\
\hline \multirow[t]{4}{*}{ WER II } & & Pretest & 0.67 & $(0.12)$ & 60 & 5.59 & $<.01$ & - \\
\hline & & Treatment & 0.17 & $(0.10)$ & 24 & 1.60 & 0.12 & 0.78 \\
\hline & Random & Intercept & 0.02 & 0.37 & - & - & - & - \\
\hline & & Residual & 0.05 & 0.46 & - & - & - & - \\
\hline Persuasive & Fixed & Intercept & 0.22 & $(0.09)$ & 31 & 2.45 & 0.02 & - \\
\hline \multirow[t]{4}{*}{ WER III } & & Pretest & 0.63 & $(0.09)$ & 60 & 6.77 & $<.01$ & - \\
\hline & & Treatment & 0.16 & $(0.08)$ & 24 & 2.05 & 0.05 & 1.06 \\
\hline & Random & Intercept & 0.01 & 0.33 & - & - & - & - \\
\hline & & Residual & 0.02 & 0.39 & - & - & - & - \\
\hline Persuasive & Fixed & Intercept & 1.55 & $(1.33)$ & 27 & 1.16 & 0.26 & - \\
\hline Words per & & Pretest & 0.81 & $(0.17)$ & 54 & 4.87 & $<.01$ & - \\
\hline \multirow[t]{3}{*}{ T-unit } & & Treatment & 1.21 & $(1.18)$ & 13 & 1.02 & 0.32 & 0.38 \\
\hline & Random & Intercept & 1.18 & 1.04 & - & - & - & - \\
\hline & & Residual & 10.06 & 1.78 & - & - & - & - \\
\hline Persuasive & Fixed & Intercept & 0.25 & $(0.12)$ & 25 & 2.19 & 0.04 & - \\
\hline$\%$ complete & & Pretest & 0.50 & $(0.11)$ & 59 & 4.41 & $<.01$ & - \\
\hline \multirow[t]{3}{*}{ sentences } & & Treatment & 0.16 & $(0.11)$ & 26 & 1.39 & 0.18 & 0.69 \\
\hline & Random & Intercept & 0.03 & 0.41 & - & - & - & - \\
\hline & & Residual & 0.05 & 0.48 & - & - & - & - \\
\hline
\end{tabular}




\begin{tabular}{lllllllll}
\hline Outcome & Type & Effect & Est. & $S E / S D$ & $d f$ & $t$ & $p$ & Size \\
\hline SORT-R3 & Fixed & Intercept & 12.91 & $(5.63)$ & 22 & 2.29 & 0.03 & - \\
& & Pretest & 0.89 & $(0.05)$ & 55 & 16.36 & $<.01$ & - \\
& & Treatment & 1.20 & $(4.91)$ & 17 & 0.24 & 0.81 & 0.11 \\
& \multirow{2}{*}{ Random } & Intercept & 43.45 & 2.57 & - & - & - & - \\
& & Residual & 120.60 & 3.31 & - & - & - & - \\
\hline
\end{tabular}

Note . Est. = Estimate (regression fixed effects or variance for random effects: see Equation 1). Dashes indicate that an estimate is not applicable. $S E=$ standard error in parentheses. $S D=$ standard deviation for random effect. Size $=$ treatment effect size (divided by the residual $S D$, akin to a Hedges' $g$ ).

Table 8. Descriptive statistics for personal narrative language outcomes

\begin{tabular}{|c|c|c|c|c|c|}
\hline \multirow{2}{*}{ Outcome Test } & \multirow{2}{*}{ Group } & \multicolumn{2}{|c|}{ Pretest } & \multicolumn{2}{|c|}{ Posttest } \\
\hline & & $M$ & $S D$ & $M$ & $S D$ \\
\hline \multirow[t]{2}{*}{ WER I } & BAU & 0.2 & 0.3 & 0.2 & 0.2 \\
\hline & Treatment & $0.1^{*}$ & 0.1 & 0.2 & 0.2 \\
\hline \multirow[t]{2}{*}{ WER II } & BAU & 0.6 & 0.3 & 0.6 & 0.3 \\
\hline & Treatment & $0.4^{*}$ & 0.3 & 0.6 & 0.3 \\
\hline \multirow[t]{2}{*}{ WER III } & BAU & 0.8 & 0.3 & 0.7 & 0.3 \\
\hline & Treatment & $0.5^{*}$ & 0.3 & 0.7 & 0.3 \\
\hline \multirow[t]{2}{*}{ Words per T-unit } & BAU & 5.1 & 2.6 & 4.6 & 2.4 \\
\hline & Treatment & $3.8^{*}$ & 2.3 & 5.3 & 2.1 \\
\hline \multirow[t]{2}{*}{$\%$ complete sentences } & BAU & 0.7 & 0.3 & 0.7 & 0.3 \\
\hline & Treatment & $0.5^{*}$ & 0.3 & 0.7 & 0.3 \\
\hline
\end{tabular}

Note. $*=$ Treatment statistically significantly lower than BAU at pretest $(\mathrm{p}<.05)$.

Table 9. Descriptive statistics for persuasive language outcomes

\begin{tabular}{|c|c|c|c|c|c|}
\hline \multirow{2}{*}{ Outcome Test } & \multirow{2}{*}{ Group } & \multicolumn{2}{|c|}{ Pre M } & \multicolumn{2}{|c|}{ Post M } \\
\hline & & $M$ & $S D$ & $M$ & $S D$ \\
\hline \multirow[t]{2}{*}{ WER I } & $\mathrm{BAU}$ & 0.3 & 0.3 & 0.2 & 0.2 \\
\hline & Treatment & $0.1^{*}$ & 0.1 & 0.1 & 0.2 \\
\hline \multirow[t]{2}{*}{ WER II } & $\mathrm{BAU}$ & 0.6 & 0.3 & 0.5 & 0.3 \\
\hline & Treatment & $0.3^{*}$ & 0.3 & 0.5 & 0.3 \\
\hline \multirow[t]{2}{*}{ WER III } & BAU & 0.8 & 0.2 & 0.7 & 0.3 \\
\hline & Treatment & $0.5^{*}$ & 0.3 & 0.7 & 0.3 \\
\hline \multirow[t]{2}{*}{ Words per T-unit } & BAU & 6.1 & 2.6 & 6.5 & 4.8 \\
\hline & Treatment & $4.1^{*}$ & 2.9 & 6.3 & 3.7 \\
\hline \multirow[t]{2}{*}{$\%$ complete sentences } & BAU & 0.7 & 0.3 & 0.6 & 0.4 \\
\hline & Treatment & $0.4^{*}$ & 0.3 & 0.7 & 0.3 \\
\hline
\end{tabular}

Note. $*=$ Treatment statistically significantly lower than BAU at pretest $(\mathrm{p}<.05)$. 
Table 10. Descriptive statistics for word identification (SORT-R3)

\begin{tabular}{llllll}
\hline \multirow{2}{*}{ Group } & Pretest & & & Posttest & \\
\cline { 2 - 3 } \cline { 5 - 6 } & $M$ & $S D$ & & $M$ & $S D$ \\
\hline BAU & 71.9 & 44.5 & & 76.2 & 44.8 \\
Treatment & 60.4 & 24.1 & & 70.1 & 26.9 \\
\hline
\end{tabular}

\section{Discussion}

The purpose of this small-scale study was to pilot SIWI in the later elementary grades and to begin to examine the extent to which it may impact students' discourse-level writing skills, written language clarity and complexity, and word identification abilities. While there are limitations to the study (detailed below), there are also reasons to believe the intervention holds promise for this age group.

During the 9-week instructional quarters, genre-specific writing scores among treatment group students improved an average of 0.7 to 0.9 rubric points compared to 0.1 mean increases among comparison group students. The results of the multilevel analysis for writing traits across both genres indicated effect sizes of 0.53 to 2.01. In regard to written language accuracy, students in the treatment group showed gains in word efficiency ratios of 0.1 to 0.2 on average, and an increase in complete sentences by $20-30 \%$, while students in the BAU group demonstrated no gains with these variables. Written language complexity, as measured by words per $t$-unit, increased by 1.5 words per $t$-unit on personal narrative writing and 2.2 words per $t$-unit on persuasive writing among treatment group students in comparison to declines ( -0.5 words per $t$-unit) or negligible gains $(+0.4$ words per $t$-unit), on average, among students in the comparison group. Treatment effects for the written language outcomes ranged from 0.38 to 1.20; however, not all persuasive language outcomes were statistically significant at the 0.05 level. There were no substantial differences identified between groups on the SORT-R word identification variable.

Overall findings of the study indicate an advantage to students in the SIWI treatment group over participants in the BAU group with respect to gains in writing traits, written language accuracy, and written language complexity. These differences were detected despite comparison group teachers having an advantage in years of teaching experience--an average of 17 years compared to 7 years among treatment group teachers. At the same time, students in the treatment group scored consistently lower on writing and language pretest measures, and perhaps the lowest students had the most to gain from the intervention. Educational implications and limitations are further explored below.

\subsection{Interpretations and Educational Implications}

The SIWI PD program is a longitudinal 3-year training program, during which teachers have demonstrated steady increases in their instructional fidelity ratings, from $74 \%$ on average after one year of $\mathrm{PD}$, to $85 \%$ after 2 years, and 94\% after 3 years (Wolbers, Dostal, Skerrit \& Stephenson, 2016). Instructional fidelity in this study was an average of $75 \%$, and further analysis showed teachers consistently implemented a higher number of interactive instruction principles compared to strategic instruction and linguistic/ metalinguistic principles. It may be that interactive writing is cognitively demanding of new implementers due to its spontaneous nature in which teachers are dynamically assessing and making contingently responsive instructional decisions. Since guided writing relies upon group interactions, teachers may focus initial efforts on honing dialogic approaches. This leads to a question of whether partial implementation of SIWI principles has the ability to positively impact students' outcomes. The results of this small-scale study are promising, yet we suggest that fuller enactment of SIWI major principles would lead to greater student gains. The benefits of strategy instruction in writing at the elementary level, for example, are clearly documented in the literature (Graham et al., 2012). Additionally, prior SIWI studies, where teachers demonstrate full enactment of principles, and flexibly attend to $\mathrm{d} / \mathrm{hh}$ students' specific language needs in the language zone, appear to report the strongest student outcomes (Dostal \& Wolbers, 2014; Wolbers, 2008a). Future studies examining the extent to which different levels of teacher instructional fidelity impact students' outcomes could be further revealing.

Due to higher enactment of interactive instruction in this study, we believe learning was largely mediated through interactive, co-constructed writing (c.f., Thompson, 2013). We might attribute gains largely to the process of establishing authentic purpose and audience for writing, and then collaboratively engaging in problem solving and decision making during writing. Students are apprenticed in how to think about, talk about, and do the writing (Englert \& Dunsmore, 2002), which then transfers to their independent attempts. Successful classroom interactions about writing fully engage participants in the task, and in doing so, have potential to develop new 
conceptual understandings. New understandings developed during collaborative activity about, for example, genre features or complete sentences, then transfer to independently written English (Rathmann, Mann \& Morgan, 2007; Wilbur, 2000).

It should be noted that students receiving SIWI evidenced progress with written language clarity and complexity which was not observed among students in the comparison group, even though all comparison group teachers reported spending considerable time on English grammar practice. We speculate two possible reasons for this. First, SIWI as a guided, collaborative writing process requires students to actively participate and communicate with their classmates and teachers. When a teacher or student's comments are not understood, the group moves to the language zone to repair breakdowns in communication and arrive to a point of shared understanding. This ensures that the classroom talk about writing is occurring at a level of complexity that is fully accessible to students, which creates an optimal environment for language learning. Prior research indicates that, as a result of SIWI, students become increasingly more able to express their ideas through ASL as well as written language (Dostal \& Wolbers, 2014).

Second, students involved in SIWI are provided with English grammar practice, but it is contextualized within purposeful writing. For example, when writing a letter to the principal to persuade her that the school should invest in a set of iPads, the class might begin by planning an argument with supporting examples, and the process of engaging in such complex thinking then drives the need for complex written language (Nippold, 2005). The authenticity of the writing activity then drives frequent rereading and revising in order to publish a piece that is grammatically correct.

In this study, students' written language appeared to be positively impacted across genres; however, there were stronger outcomes for personal narrative writing compared to persuasive. This may be related to abstract and complex language features of expository text that convey "why", compared to the language features needed to tell "what happened" in personal narratives (Schleppegrell, 2010). The language of written arguments includes expanded nominal groups, abstract ideas, technical language, connectives, and emotive features (Derewianka, 1990; Schleppegrell, 2010), which likely contribute to greater challenges for $\mathrm{d} / \mathrm{hh}$ writers with limited linguistic resources.

In taking a closer look at the writing outcomes, students in the treatment group increased nearly a point on writing rubrics for traits such as organizing ideas, detailing events (personal narrative), or justifying an opinion with reasons (persuasive). Group differences were statistically significant, and effect sizes were moderate to large. As a small-scale pilot study, the intervention may show a degree of promise for teaching writing to elementary $\mathrm{d} / \mathrm{hh}$ students. The challenge in interpreting the data, however, is that $\mathrm{d} / \mathrm{hh}$ students, on average, began the study with extremely low writing scores of 1 (demonstrates little to no skill) to 2 (demonstrates marginal skill). In comparison, $86 \%$ of 4 th grade students are at or above a basic level, constituted largely by a score of 3 or higher on similar NAEP rubrics (Persky, Daane \& Jin, 2003). While we can identify a trend toward basic writing skills, we also recommend lengthier studies of SIWI to gain a better understanding of the longitudinal trajectory.

\subsection{Limitations and Future Directions}

There are several limitations of the study. The most prominent limitation was that it was based on a small convenience sample of teachers and their respective students who were participating in an IES grant project. Students were matched on select variables such as age, grade, and reading level, which resulted in groups with no statistically significant differences in these background characteristics. However, the treatment group had lower pretest performance on the majority of the outcomes. While pretest was used in the analytic model, it is possible that the treatment children had more to gain or that basic skills are easier to learn, resulting in larger gains for the SIWI group. Models with pretest by treatment interactions did not find significant effects, but the sample size was likely too small for such interactions to be reliably detected. While factors other than treatment could have contributed to differences in this small pilot study, the model suggests that effect sizes (gains above pretest) were uniformly positive across several outcomes. Still, a randomized controlled trial with a larger sample of students is recommended for future research.

Second, it is possible that teachers involved in the SIWI treatment group were more motivated to provide language and literacy instruction to students than teachers in the comparison group. There are few writing instruction programs specifically designed for $\mathrm{d} / \mathrm{hh}$ students, and due to this, teachers having received SIWI PD may exhibit greater enthusiasm for teaching writing which can impact the performance of students. Similarly, SIWI teachers may have grown in their overall knowledge of writing instruction by participating in the study. While our analysis accounted for teacher-level differences, a larger and more varied sample of teachers is needed to corroborate these findings. 
Third, the description of comparison group instruction and the amount of time allocated to literacy was based on teachers' self-reporting. Observations were not conducted in the BAU classes and such data are necessary to strengthen the validity of the planned instructional difference between SIWI classrooms and other forms of instruction.

Another future direction is to explore the potential impact that SIWI has on word identification ability and other reading skills. While a statistically significant difference between groups on word identification ability was not found in this study, a moderate effect has been reported in a previous SIWI study (Wolbers, 2008a). Further, an analysis of the disaggregated SORT-R output by teachers in this study (see Skerrit, 2015) revealed that students' gains from two SIWI classrooms far surpassed those of other classes. A closer examination of the reading and rereading practices in these two classes may reveal ways in which teachers strategically promote greater word awareness and recognition during SIWI.

\section{Conclusion}

This quasi-experimental study involved 63, 3rd-5th d/hh students across SIWI and BAU conditions. In 9 weeks of instruction on personal narrative writing, the treatment group made significantly greater progress with genre-specific writing skills as well as written language complexity and accuracy. Effect sizes for gains were uniformly positive $(M=0.93 ; S D=0.45)$. Outcomes after 9 weeks of persuasive writing followed the same trends of improvement although not all gains were statistically significant at the 0.05 level. The findings of this study suggest good promise for implementing evidence-based writing approaches with $\mathrm{d} / \mathrm{hh}$ students, while additionally being attuned to their diverse language needs.

\section{Acknowledgements}

The research reported here was supported by the Institute of Education Sciences, U.S. Department of Education, through Grant R324A120085 to the University of Tennessee. The opinions expressed are those of the authors and do not represent views of the Institute or the U.S. Department of Education.

\section{References}

Allen, T. E., \& Anderson, M. L. (2010). Deaf students and their classroom communication: An evaluation of higher order categorical interactions among school and background characteristics. Journal of Deaf Studies and Deaf Education, 15(4), 334-347. https://doi.org/10.1093/deafed/enq034

Applebee, A. N. (2000). Alternative models of writing development. In R. Indrisano \& J. Squire (Eds.), Perspectives on writing: Research, theory and practice (pp. 90-110). Newark, DE: International Reading Association.

Burbules, N. (1993). Dialogue in teaching. New York, NY: Teachers College Press.

Derewianka, B. (1990). Exploring how texts work. Newtown, Australia: Primary English Teaching Association.

Dostal, H., Bowers, L., Wolbers, K., \& Gabriel, R. (2015). "We are authors": A qualitative analysis of deaf students writing during one year of Strategic and Interactive Writing (SIWI). Review of Disability Studies International, 11(2), 1-19.

Dostal, H., \& Wolbers, K. (2014). Developing language and writing skills of deaf and hard of hearing students: A simultaneous approach. Literacy Research and Instruction, 53(3), 245-268. https://doi.org/10.1080/19388071.2014.907382

Ellis, R., Loewen, S., Elder, C., Erlam, R., Philp, J. \& Reinders, H. (2009). Implicit and explicit knowledge in second language learning, testing and teaching. Bristol, UK: Multilingual Matters.

Englert, C. S., \& Dunsmore, K. (2002). A Diversity of teaching and learning paths: Teaching writing in situated activity. In J. Brophy (Ed.), Social constructivist teaching: Affordances and constraints (pp. 81-130). Boston, MA: JAI.

Flower, L. S. \& Hayes, R. J. (1980). The cognition of discovery: Defining a rhetorical problem. College Composition and Communication, 31, 21-32. https://doi.org/10.2307/356630

Graham, S. (in press). A writer(s) within community model of writing. In C. Bazerman, V. Berninger, D. Brandt, S. Graham, J. Langer, S. Murphy, P. Matsuda, D. Rowe, \& M. Schleppegrell (Eds.), The lifespan development of writing. Urbana, IL: National Council of English.

Graham, S., Harris, K. R., \& McKeown, D. (2013). The writing of students with LD and a meta-analysis of SRSD writing intervention studies: Redux. In L. Swanson, K. R. Harris, \& S. Graham (Eds.), Handbook of learning 
disabilities (2 ${ }^{\text {nd }}$ Edition; pp. 405-438). New York, NY: Guilford Press.

Graham, S., Harris, K. R., \& Santangelo, T. (2015). Research-based writing practices and the common core: Meta-analysis and Meta-Synthesis. Elementary School Journal, 115(4), 498-522. https://doi.org/10.1086/681964

Graham, S., McKeown, D., Kiuhara, S., \& Harris, K. R. (2012). A meta-analysis of writing instruction for students in the elementary grades. Journal of Educational Psychology, 104(4), 879-896. https://doi.org/10.1037/a0029185

Graham, S. \& Perin, D. (2007). Writing next: Effective strategies to improve writing of adolescents in middle and high schools - A report to Carnegie Corporation of New York. Washington, DC: Alliance for Excellent Education.

Harris, K. R., \& Graham, S. (2009). Self-regulated strategy development in writing: Premises, evolution, and the future. British Journal of Educational Psychology (monograph series), number 6, 113-135.

Harris, K. R., Graham, S., Friedlander, B. \& Laud, L. (2013). Bring powerful writing strategies into your classroom! Why and how. The Reading Teacher, 66(7), 539-542. https://doi.org/10.1002/TRTR.1156

Harris, K. R., Graham, S., Mason, L., \& Saddler, B. (2002). Developing self-regulated writers. Theory into Practice, 41, 110-115.

Hayes, J. R. (1996). A new framework for understanding cognition and affect in writing. In C.M. Levy \& S. Ransdell (Eds.), The science of writing:Theories, methods, individual differences, and applications (pp. 1-27). Mahwah, NJ: Lawrence Erbaum Associates.

Hayes, J. R. (2006). New directions in writing theory. In C.A. MacArthur, S. Graham \& J. Fitzgerald (Eds.), Handbook of writing research (pp. 28-40). New York, NY: The Guilford Press.

Hayes, J. R. \& Flower, L. S. (1980). Identifying the organization of writing processes. In L.W. Gregg \& E.R. Steinberg (Eds.), Cognitive processes in writing (pp. 31-50). Hillsdale, NJ: Erlbaum \& Associates.

Hedges, L. V. (2007). Effect sizes in cluster randomized designs. Journal of Educational and Behavioral Statistics, $32,341-370$.

Hillocks, G. (1995). Teaching writing as reflective practice. New York, NY: Teachers College Press.

Hunt, K. W. (1965). Grammatical structures written at three grade levels (NCTE Research Report No.3). Champaign, IL: NCTE. Retrieved from http://www.eric.ed.gov/PDFS/ED113735.pdf

Jackendoff, R. (1994). Patterns in the mind. New York, NY: BasicBooks.

Krashen, S. D. (1994). The input hypothesis and its rivals. In N.C. Ellis (Ed.), Implicit and explicit learning of languages (pp. 45-77). London, England: Academic Press Limited.

Krashen, S. D. (2008). Language education: Past, present, and future. RELC Journal, 39, 178-187. https://doi.org/10.1177/0033688208092183

Lave, J., \& Wenger, E. (2003). Situated learning: Legitimate peripheral participation. New York, NY: Cambridge University Press.

Lederberg, A. R., \& Spencer, P. E. (2001). Vocabulary development of deaf and hard of hearing children. In M. D. Clark, M. Marschark, \& M. Karchmer (Eds.), Context, cognition, and deafness (pp. 88-112). Washington, DC: Gallaudet University Press.

Mariage, T. V. (2001). Features of an interactive writing discourse: Conversational involvement, conventional knowledge, and internalization in "Morning Message." Journal of Learning Disabilities, 34(2), 172-196. https://doi.org/10.1177/002221940103400206

Mayer, C., Akamatsu, T., \& Stewart, D. (2002). A model for effective practice: Dialogic inquiry with students who are deaf. Exceptional Children, 68(4), 485-505. https://doi.org/10.1177/001440290206800405

Mitchell, R., \& Karchmer, M. A. (2004). Chasing the mythical ten percent: Parental hearing status of deaf and hard of hearing students in the United States. Sign Language Studies, 4(2), 138-163, https://doi.org/10.1353/sls.2004.0005

Morere, D., \& Allen, T. (Eds.). (2012). Assessing literacy in deaf individuals: Neurocognitive measurement and predictors. Springer Science \& Business Media.

National Assessment Governing Board, US Department of Education (2010). Writing framework for the 2011 
national assessment of educational progress. Washington, DC: Driscoll, DP.

Nippold, M., Ward-Lonergan, J., \& Fanning, J. (2005). Persuasive writing in children, adolescents, and adults: A study of syntactic, semantic, and pragmatic development. Language, Speech, and Hearing Services in Schools, 36, 125-138. https://doi.org/10.1044/0161-1461

O'Neill, R., Arendt, J., \& Marschark, M. (2014). Report from the Achievement and Opportunities for Deaf Students in the United Kingdom: From research to practice project. Edinburgh, Scotland: University of Edinburgh.

Paradis, M. (2009). Declarative and procedural determinants of second languages. Amsterdam, Netherlands: John Benjamins Publishing Co.

Persky, H. R., Daane, M. C., \& Jin, Y. (2003). The nation's report card: Writing 2002 (NCES Report No. 2003-529). Washington, D.C.: National Center for Education Statistics.

Pinker, S. (1995). The language instinct: How the mind creates language. New York, NY: Harper Collins Publishers, Inc.

Qi, S., \& Mitchell, R. E. (2012). Large-scaled academic achievement testing of deaf and hard-of-hearing students: Past, present, and future. Journal of Deaf Studies and Deaf Education, 17, 1-18. https://doi.org/10.1093/deafed/enr028

Rathmann, C., Mann, W., \& Morgan, G. (2007). Narrative structure and narrative development in deaf children. Deafness and Education International, 9(4), 187-196. https://doi.org/10.1002/dei.228

Scardamalia, M., \& Bereiter, C. (1986). Research on written composition. In M. C. Wittrock (Ed.), Handbook of research on teaching $\left(3^{\text {rd }}\right.$ ed., pp. 778-803). New York: MacMillan.

Schleppegrell, M. J. (2010). The language of schooling: A functional linguistics perspective. New York, NY: Routledge.

Singleton, J. L., Morgan, D., DiGello, E., Wiles, J., \& Rivers, R. (2004). Vocabulary use by low, moderate, and high ASL-proficient writers compared to hearing ESL and monolingual speakers. Journal of Deaf Studies and Deaf Education, 9(1), 86-103. https://doi.org/10.1093/deafed/enh011

Skerrit, P. (2015). Practices and routines in SIWI lessons that develop reading skills. (Doctoral dissertation). The University of Tennessee, Knoxville, TN.

Slosson, R. L., \& Nicholson, C. L. (2008). Slosson Oral Reading Test Revised. East Aurora, NY: Slosson Educational Publications, Inc.

Strassman, B. K., \& Schirmer, B. (2013). Teaching writing to deaf students: Does research offer evidence for practice? Remedial and Special Education, 34(3), 166-179. https://doi.org/10.1177/0741932512452013

Thompson, I. (2013). The mediation of learning in the Zone of Proximal Development through a co-constructed writing activity. Research in the Teaching of English, 47(3), 247-276. https://doi.org/10.1111/j.1754-8845.2011.01117

Tye-Murray, N. (1994). Let's converse: A "how-to" guide to develop and expand conversational skills of children and teenagers who are hearing impaired. Washington, D.C.: Alexander Graham Bell Association for the Deaf. Inc.

Vygotsky, L. S. (1978). Mind in society: The development of the higher psychological processes. Cambridge, MA: Harvard University Press.

Vygotsky, L. (1994). Thought and language. Cambridge, MA: The Massachusetts Institute of Technology Press.

Ward, I. (1994). Literacy ideology, and dialogue: Towards a dialogic pedagogy. Albany, NY: State University of New York Press.

Wells, G. (2000). Dialogic inquiry in education: Building on the legacy of Vygotsky. In C. D. Lee \& P. Smagorinsky (Eds.), Vygotskian perspectives on literacy research (pp. 51-85). New York, NY: Cambridge University Press.

Wertsch, J. V. (1991). Voices of the mind: A sociocultural approach to mediated action. Cambridge, MA: Harvard University Press.

White, A. (2007). A tool for monitoring the development of written English: T-unit analysis using the SAWL. American Annals of the Deaf, 152(1), 29-41. https://doi.org/10.1353/aad.2007.0016

Wilbur, R. (2000). The use of ASL to support the development of English and literacy. Journal of Deaf Studies and 
Deaf Education, 5(1), 81-104. https://doi.org/10.1093/deafed/5.1.81

Williams, C. \& Mayer, C. (2015). Writing in young deaf children. Review of Educational Research, 85(4), 630-666. https://doi.org/10.3102/0034654314564882

Wolbers, K. (2008a). Strategic and Interactive Writing Instruction (SIWI): Apprenticing deaf students in the construction of English text. ITL International Journal of Applied Linguistics, 156, 299-326. https://doi.org/10.2143/ITL.156.0.2034441

Wolbers, K. (2008b). Using balanced and interactive writing instruction to improve the higher order and lower order writing skills of deaf students. Journal of Deaf Studies and Deaf Education, 13(2), 255-277. https://doi.org/10.1093/deafed/enm052

Wolbers, K. (2010). Using ASL and print-based sign to build fluency and greater independence with written English among deaf students. L1-Educational Studies in Language and Literature, 10(1), 99-125. Retrieved from http://11.publication-archive.com/publication/1/333

Wolbers, K., Bowers, L., Dostal, H., \& Graham, S. C. (2013). Deaf writers' application of ASL knowledge to English. International Journal of Bilingual Education and Bilingualism, 17(4), 410-428. https://doi.org/10.1080/13670050.2013.816262

Wolbers, K., Dostal, H., \& Bowers, L. (2012). “I was born full deaf.” Written language outcomes after one year of Strategic and Interactive Writing Instruction (SIWI). Journal of Deaf Studies and Deaf Education, 17(1), 19-38. https://doi.org/10.1093/deafed/enr018

Wolbers, K., Dostal, H., Graham, S., Cihak, D., Kilpatrick, J., \& Saulsburry, R. (2015). The writing performance of elementary students receiving Strategic and Interactive Writing Instruction. Journal of Deaf Studies and Deaf Education, 20(4), 385-398. https://doi.org/10.1093/deafed/env022

Wolbers, K., Dostal, H., Skerrit, P., \& Stephenson, B. (2016). A three-year study of a professional development program's impact on teacher knowledge and classroom implementation of Strategic and Interactive Writing Instruction. Journal of Educational Research, 110, 61-71. https://doi.org/10.1080/00220671.2015.1039112

\section{Copyrights}

Copyright for this article is retained by the author(s), with first publication rights granted to the journal.

This is an open-access article distributed under the terms and conditions of the Creative Commons Attribution license (http://creativecommons.org/licenses/by/4.0/). 